\title{
Comparison of sodium dithionite and glucose as a reducing agent for natural indigo dyeing on cotton fabrics
}

\author{
Laksanawadee Saikhao ${ }^{1}$, Jantip Setthayanond ${ }^{2}$,Thitinun Karpkird ${ }^{1}$ and Potjanart Suwanruji ${ }^{1}$ \\ ${ }^{1}$ Department of Chemistry, Faculty of Science, Kasetsart University, Bangkok, 10900 Thailand \\ ${ }^{2}$ Department of Textile Science, Faculty of Agro-Industry, Kasetsart University, Bangkok, 10900 Thailand
}

\begin{abstract}
A traditional reducing agent in an indigo dyeing process with cotton fabrics is sodium dithionite $\left(\mathrm{Na}_{2} \mathrm{~S}_{2} \mathrm{O}_{4}\right)$ which is environmentally unfavorable because the resulting by-products cause various problems to the disposal wastewaters. In this research, glucose was used as a possible replacement of $\mathrm{Na}_{2} \mathrm{~S}_{2} \mathrm{O}_{4}$ in indigo dyeing. The comparison of reduction power of $\mathrm{Na}_{2} \mathrm{~S}_{2} \mathrm{O}_{4}$ and glucose for natural indigo dyeing on cotton fabrics based on reduction potential was analyzed. The optimum reduction temperature for natural indigo dye of both reducing agents was at $70^{\circ} \mathrm{C}$. The reduction time did not have a significant effect on the reduction potential under the condition studied. $\mathrm{Na}_{2} \mathrm{~S}_{2} \mathrm{O}_{4}$ could give higher color strength than glucose. However, wash fastness of the fabric samples from a glucose reduction was slightly better than $\mathrm{Na}_{2} \mathrm{~S}_{2} \mathrm{O}_{4}$ ones. Hence, glucose virtually has a potential to be used as a green reducing agent in natural indigo dyeing.
\end{abstract}

\section{Introduction}

Natural indigo is an ancient vat blue dye that can be extracted from native indigo-bearing plants, especially from the leaves. Indigofera, Isatis tinctoria and Persicaria tinctoria are examples of indigo-bearing plants. Indican is hydrolyzed by enzyme to indoxyl and glucose. When indoxyl is exposed to oxygen by vigorously whisked, the indoxyl is converted to indigo blue [1] as shown in Figure 1.

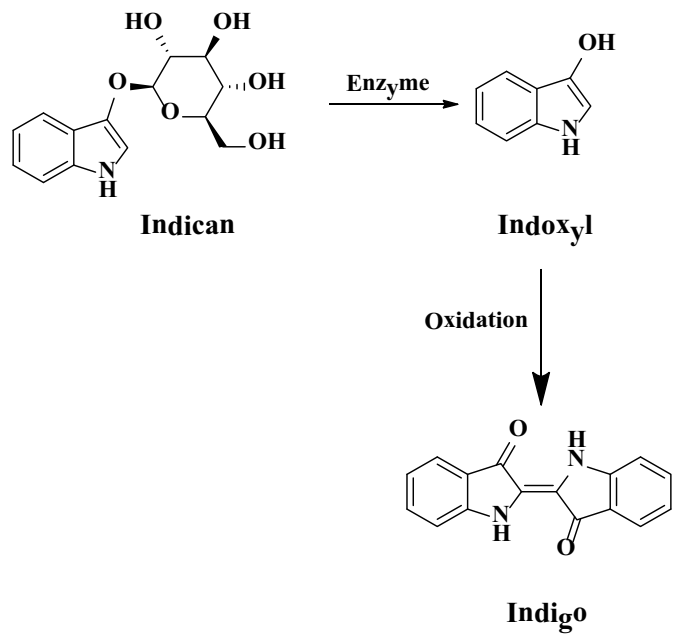

Figure 1. Production of indigo dye from indigo plants.

In Thailand, indigo is called "Kramm" and indigo plants, Indigofera tinctoria, are grown mainly in the north-east areas such as Surin, Udon Thani, Kalasin and Sakon nakhon [2]. The water insoluble indigo pigments consist of a conjugated dicarbonyl system [3] that can be reduced to a leuco form by a reducing agent in an alkaline condition $(\mathrm{pH}$ 11-14) before applying on cellulosic fibers [4]. Only air oxidation is enough to convert a leuco dye to the original indigo pigment inside the fibers [5]. Figure 2 shows the oxidation and reduction reactions of indigo dyes.

The traditional reducing agent used is sodium dithionite $\left(\mathrm{Na}_{2} \mathrm{~S}_{2} \mathrm{O}_{4}\right)$ because of its effective reduction for indigo dyes [6]. It is also called sodium hydrosulphite or hydros [7]. Typically, the amount of $\mathrm{Na}_{2} \mathrm{~S}_{2} \mathrm{O}_{4}$ that is industrially used in the reduction reaction of indigo dyeing is more than the stoichiometric amount, resulting in a large amount of by-products from the process e.g. sulfite $\left(\mathrm{SO}_{3}{ }^{2-}\right)$ and sulfate $\left(\mathrm{SO}_{4}{ }^{2-}\right)$ ions [8] as shown in Equation (1).

$$
\mathrm{S}_{2} \mathrm{O}_{4}{ }^{2-}+\mathrm{O}_{2}+2 \mathrm{OH} \longrightarrow \mathrm{SO}_{3}{ }^{2-}+\mathrm{SO}_{4}{ }^{2-}+\mathrm{H}_{2} \mathrm{O}
$$

(1)

These ions can cause ecological problems, for example, $\mathrm{SO}_{3}{ }^{2-}$ can be easily oxidized to $\mathrm{SO}_{4}{ }^{2-}$ and the high concentration of $\mathrm{SO}_{4}{ }^{2-}$ can cause corrosion in concrete pipes [9]. Thus, our approach in this work is to use glucose as a green reducing agent instead of $\mathrm{Na}_{2} \mathrm{~S}_{2} \mathrm{O}_{4}$ in natural indigo dyeing process. Glucose is a reducing sugar that has an aldehyde functional group which can be oxidized to carboxylic acid and simultaneously reduce indigo pigments to leuco dyes. The comparison of glucose and $\mathrm{Na}_{2} \mathrm{~S}_{2} \mathrm{O}_{4}$ was studied in terms of their reduction potential and optimal dyeing conditions. The 
color strength $(\mathrm{K} / \mathrm{S})$ and wash fastness of dyed cotton fabrics were also examined.

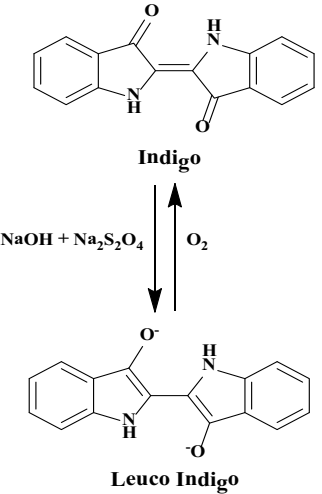

Figure 2. Oxidation-reduction of indigo.

\section{Experimental}

\subsection{Materials}

Natural indigo paste was purchased from Ban Tam Tao, Sakon Nakhon, Thailand. Cotton fabrics was supplied by P.S.Jevasy. Co. Ltd, Thailand. $\mathrm{Na}_{2} \mathrm{~S}_{2} \mathrm{O}_{4}$, glucose and $\mathrm{NaOH}$ used were AR grade.

\subsection{Methods}

\subsubsection{Preparation of indigo dye and cotton fabrics}

Natural indigo paste was vacuum filtered and oven-dried at $60^{\circ} \mathrm{C}$ for $24 \mathrm{hrs}$. The dried indigo powder was milled and stored at room temperature. Cotton fabrics were scoured at $90-95^{\circ} \mathrm{C}$ for $45 \mathrm{~min}$ in a bath containing $4 \mathrm{~g} / \mathrm{L}$ $\mathrm{NaOH}$ and $1 \mathrm{~g} / \mathrm{L}$ wetting agent using 30:1 liquor ratio. The scoured cotton was rinsed with hot and cold water, respectively, and then air-dried.

\subsubsection{Reduction and dyeing conditions}

Cotton fabrics $(2 \mathrm{~g})$ were dyed with natural indigo $(4 \mathrm{~g})$ using a liquor ratio of $50: 1,12 \mathrm{~g} / \mathrm{L} \mathrm{NaOH}, 10 \mathrm{~g} / \mathrm{L}$ $\mathrm{Na}_{2} \mathrm{~S}_{2} \mathrm{O}_{4}$ or $20 \mathrm{~g} / \mathrm{L}$ glucose. The reduction temperature $\left(T_{R}\right)$ was set from 30 to $90^{\circ} \mathrm{C}$ with the reduction time $\left(t_{R}\right)$ varied from 0 to $60 \mathrm{~min}$. The cotton fabrics were put into dyebath and the dyeing temperature $\left(\mathrm{T}_{\mathrm{D}}\right)$ was set at $30^{\circ} \mathrm{C}$ and dyeing time $\left(t_{D}\right)$ was carried out at 10, 20 and 30 min as shown in Figure 3. The dyed fabrics were washed in distilled water until the water was neutral and then airdried.

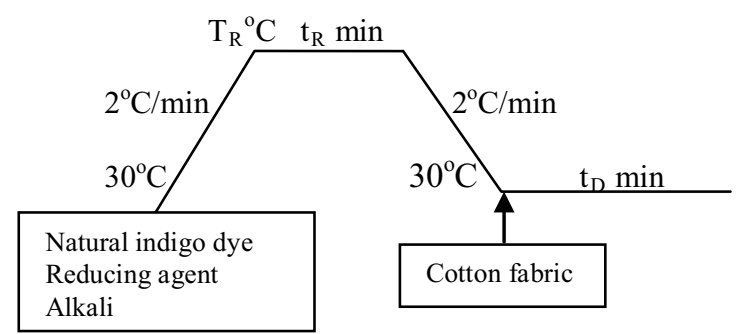

Figure 3. Dyeing process of natural indigo dye on cotton fabrics.

\subsubsection{Reduction potential measurement}

Reduction potential of all reducing dye solutions was measured by an oxidation-reduction potential (ORP) platinum electrode and the $\mathrm{Ag} / \mathrm{AgCl}$ reference electrode with $\mathrm{KCl}$ electrolyte, connected to a $\mathrm{pH}$ meter (Metter Toledo, Inlab) and recorded in $(\mathrm{mV})$ [10]. The experiment set up is shown in Figure 4. The reducing power of reducing agents was compared.

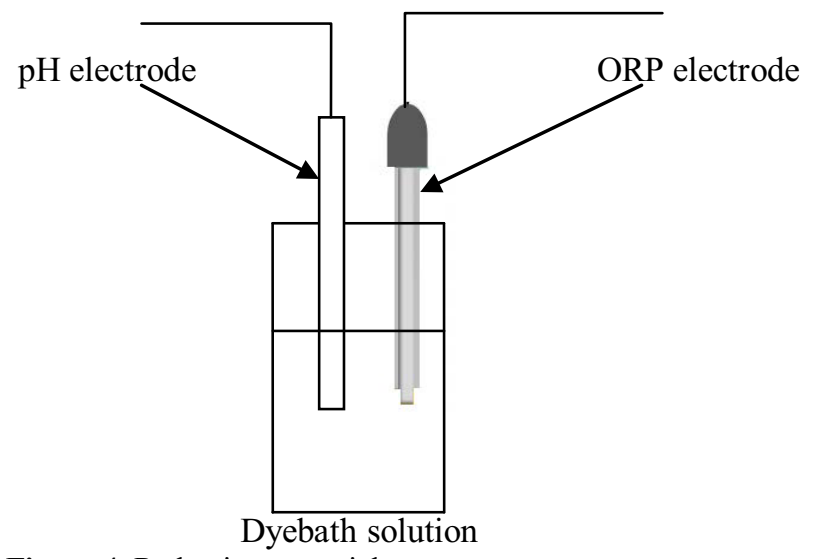

Figure 4. Reduction potential measurement set up.

\subsubsection{Color measurement}

The determination of color strength $(\mathrm{K} / \mathrm{S})$ values of all dyed cotton fabric samples was carried out on a Macbeth ColorEye 7000 Spectrophotometer under Illuminant $\mathrm{D}_{65}$ at $10^{\circ}$ observer position. The $\mathrm{K} / \mathrm{S}$ values were calculated from Kubelka-Munk Equation (2).

$$
\mathrm{K} / \mathrm{S}=\frac{(1-\mathrm{R})^{2}}{2 \mathrm{R}}
$$

where $\mathrm{R}$ is the reflection of all dyed cotton fabric samples [11].

\subsubsection{Wash fastness}

The dyed samples were evaluated for the wash fastness according to the ISO 105-C06: 1994. The fastness properties were compared among the fabric samples using different reducing agents [12]. The color change of the dyed fabric samples and staining on the multifiber fabric were assessed by a grey scale for color change and staining, respectively. The level of grey scale is rated from 1 to 5. Level 1 refers to the highest degree of shade change or staining, while level 5 refers to no shade change or no staining.

\section{Results and discussion}

\subsection{Reduction temperature $\left(T_{R}\right)$}

Figure 5 shows the plot between measured reduction potential in $\mathrm{mV}$ and $\mathrm{T}_{\mathrm{R}}$ in ${ }^{\circ} \mathrm{C}$. The optimum reduction 
temperature of indigo was at $70^{\circ} \mathrm{C}$ for both $\mathrm{Na}_{2} \mathrm{~S}_{2} \mathrm{O}_{4}$ and glucose. The redox potential of the indigo dye was reported about $-700 \mathrm{mV}$ [13]. From the experiment, the redox potentials at $70^{\circ} \mathrm{C}$ of $\mathrm{Na}_{2} \mathrm{~S}_{2} \mathrm{O}_{4}$ and glucose were $924 \mathrm{mV}$ and $-722 \mathrm{mV}$, respectively which were more negative than that of indigo. Both of them were able to use in the reduction of indigo dyes. Hence, glucose can be an alternative reducing agent in the indigo dyeing process. In the case of $\mathrm{Na}_{2} \mathrm{~S}_{2} \mathrm{O}_{4}$, as the temperature increased the reduction potential slightly increased in the negative values which is in agreement with Meksi, 2012. On the other hand, the reduction potentials of glucose above $70^{\circ} \mathrm{C}$ tended to decrease.

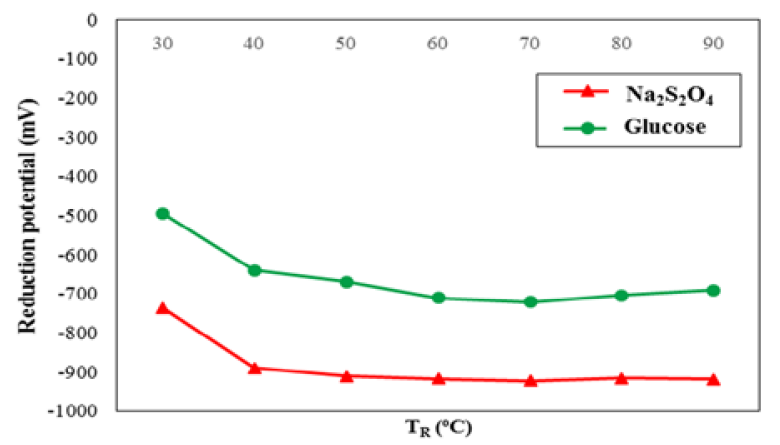

Figure 5. Reduction potentials of indigo dyeing using $\mathrm{Na}_{2} \mathrm{~S}_{2} \mathrm{O}_{4}$ and glucose as reducing agents at the designated reduction temperature.

\subsection{Reduction time $\left(t_{R}\right)$}

Figure 6 shows the effect of reduction time $\left(t_{R}\right)$ on the reduction potential of $\mathrm{Na}_{2} \mathrm{~S}_{2} \mathrm{O}_{4}$ and glucose. The reduction potentials were recorded every $10 \mathrm{~min}$ from 0 $60 \mathrm{~min}$. The results demonstrated that reduction time did not have a significant effect on the reduction potential under the conditions studied. The results indicated that it was not necessary to reduce indigo dyes longer than 10 min because the reduction potentials were about constant. The reduction potentials of $\mathrm{Na}_{2} \mathrm{~S}_{2} \mathrm{O}_{4}$ and glucose at 10 min were -906 and $-736 \mathrm{mV}$, respectively. Even though $\mathrm{Na}_{2} \mathrm{~S}_{2} \mathrm{O}_{4}$ gave higher negative reduction potential, glucose provided a negative reduction potential that was effective enough to reduce the indigo pigment to be in a soluble leuco form.

\subsection{Dyeing time $\left(t_{D}\right)$}

Leuco dyes from $\mathrm{Na}_{2} \mathrm{~S}_{2} \mathrm{O}_{4}$ and glucose reduction were applied on cotton at room temperature for 10, 20 and 30 min. After dyeing for $10 \mathrm{~min}$, the reduction potentials of the dyebath showed the least negative values as shown in Figure 7. The reduction potentials of $\mathrm{Na}_{2} \mathrm{~S}_{2} \mathrm{O}_{4}$ and glucose as shown in Table 1 were -890 and $-629 \mathrm{mV}$, respectively. These reduction potentials also corresponded to the K/S values of the dyed cotton fabrics as shown in Table 2. Dyeing cotton fabrics for $10 \mathrm{~min}$ gave the highest $\mathrm{K} / \mathrm{S}$ values. $\mathrm{Na}_{2} \mathrm{~S}_{2} \mathrm{O}_{4}$ yielded $\mathrm{K} / \mathrm{S}$ that was higher than glucose about 1 unit. However, glucose could effectively reduce the indigo dye and gave a comparable color strength on cotton fabrics. The remaining dyebath would have less environmental effect than that of $\mathrm{Na}_{2} \mathrm{~S}_{2} \mathrm{O}_{4}$.

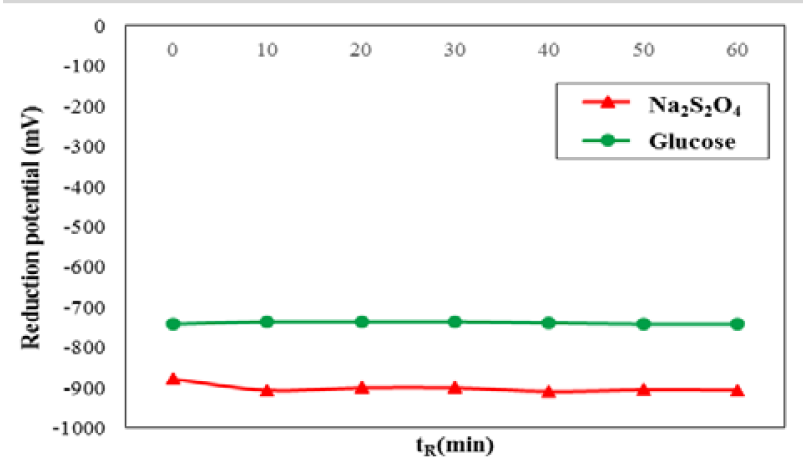

Figure 6. Reduction potentials of $\mathrm{Na}_{2} \mathrm{~S}_{2} \mathrm{O}_{4}$ and glucose in dyebath at various reduction times.

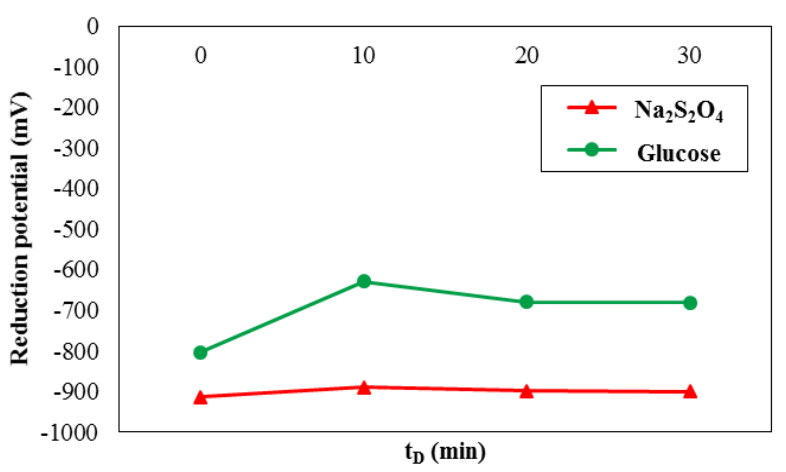

Figure 7. Evolution of reduction potential of $\mathrm{Na}_{2} \mathrm{~S}_{2} \mathrm{O}_{4}$ and glucose as reducing agents in indigo dyeing process at various times.

Table 1. Reduction potential of $\mathrm{Na}_{2} \mathrm{~S}_{2} \mathrm{O}_{4}$ and glucose as reducing agent in indigo dyeing process at various times.

\begin{tabular}{|c|c|c|c|}
\hline \multirow{2}{*}{ Reducing agent } & $\mathrm{t}_{\mathrm{D}}$ & \multicolumn{2}{|c|}{ Reduction potential (mV) } \\
\cline { 3 - 4 } & $(\mathrm{mV})$ & Before dyeing & After dyeing \\
\hline \multirow{2}{*}{$\mathrm{Na}_{2} \mathrm{~S}_{2} \mathrm{O}_{4}$} & 10 & -914 & -890 \\
\cline { 2 - 4 } & 20 & -914 & -899 \\
\cline { 2 - 4 } & 30 & -914 & -901 \\
\hline \multirow{2}{*}{ Glucose } & 10 & -804 & -629 \\
\cline { 2 - 5 } & 20 & -804 & -680 \\
\cline { 2 - 5 } & 30 & -804 & -681 \\
\hline
\end{tabular}

\subsection{Wash fastness}

Table 3 shows the wash fastness results of dyed cotton using $\mathrm{Na}_{2} \mathrm{~S}_{2} \mathrm{O}_{4}$ and glucose as reducing agents. In general, the color change and staining on multifiber were similar comparing between the fabric samples from 
$\mathrm{Na}_{2} \mathrm{~S}_{2} \mathrm{O}_{4}$ and glucose. Staining on nylon and acetate was less in the case of glucose.

Table 2. Color strength of cotton fabrics at dyeing time of 10 , 20 and $30 \mathrm{~min}$.

\begin{tabular}{|l|c|c|c|}
\hline Reducing agent & $\mathrm{t}_{\mathrm{D}}$ (min) & Dyed samples & $\mathrm{K} / \mathrm{S}$ \\
\hline $\mathrm{Na}_{2} \mathrm{~S}_{2} \mathrm{O}_{4}$ & 10 & & 7.41 \\
\cline { 2 - 4 } & 20 & & 6.39 \\
\cline { 2 - 4 } & 30 & & 7.29 \\
\hline \multirow{5}{*}{ Glucose } & 10 & & 7.41 \\
& 20 & & 6.08 \\
\cline { 2 - 4 } & 30 & & 6.33 \\
\hline
\end{tabular}

Table 3. Wash fastness of indigo dyed cotton fabrics.

\begin{tabular}{|l|c|c|c|c|c|c|c|}
\hline \multirow{2}{*}{$\begin{array}{c}\text { Reducing } \\
\text { agents }\end{array}$} & \multicolumn{7}{|c|}{ Wash fastness } \\
\cline { 2 - 8 } & SW & SAcr & SP & SN & SC & SAce & Alt \\
\hline $\mathrm{Na}_{2} \mathrm{~S}_{2} \mathrm{O}_{4}$ & \multicolumn{7}{|c|}{} \\
\hline $\mathrm{t}_{\mathrm{D}}=10 \min$ & 5 & 5 & 5 & $3-4$ & 5 & $3-4$ & 4 \\
\hline $\mathrm{t}_{\mathrm{D}}=20 \min$ & 5 & 5 & 5 & $3-4$ & 5 & $3-4$ & 4 \\
\hline $\mathrm{t}_{\mathrm{D}}=30 \min$ & 5 & 5 & 5 & $3-4$ & 5 & 3 & 4 \\
\hline Glucose & \multicolumn{7}{|c|}{} \\
\hline $\mathrm{t}_{\mathrm{D}}=10 \min$ & 5 & 5 & 5 & 4 & 5 & 4 & 4 \\
\hline $\mathrm{t}_{\mathrm{D}}=20 \min$ & 5 & 5 & 5 & 4 & 5 & $3-4$ & 4 \\
\hline $\mathrm{t}_{\mathrm{D}}=30 \min$ & 5 & 5 & 5 & 4 & 5 & $3-4$ & 4 \\
\hline
\end{tabular}

*SW: staining on wool, SAcr: staining on acrylic, SP: staining on polyester, SN: staining on nylon, SC: staining on cotton, SAce: staining on acetate and Alt: change of color

\section{Conclusions}

The reduction power of two reducing agents, $\mathrm{Na}_{2} \mathrm{~S}_{2} \mathrm{O}_{4}$ and glucose for natural indigo dyeing process was compared. The optimum reduction temperature was found to be at $70^{\circ} \mathrm{C}$, giving reduction potential of
$\mathrm{Na}_{2} \mathrm{~S}_{2} \mathrm{O}_{4}$ and glucose at $-924 \mathrm{mV}$ and $-722 \mathrm{mV}$, respectively. The optimum reduction duration was $10 \mathrm{~min}$. Reduction potentials of $\mathrm{Na}_{2} \mathrm{~S}_{2} \mathrm{O}_{4}$ and glucose corresponded to $\mathrm{K} / \mathrm{S}$ values of the dyed cotton fabrics. The $\mathrm{K} / \mathrm{S}$ values of $\mathrm{Na}_{2} \mathrm{~S}_{2} \mathrm{O}_{4}$ samples were higher than those of glucose samples about 1 unit while the wash fastness properties of the latter one were slightly better than the former one. The results indicated that glucose could effectively reduce indigo dyes to a leuco form and gave a comparable dyeing properties as compared to $\mathrm{Na}_{2} \mathrm{~S}_{2} \mathrm{O}_{4}$. Moreover, glucose was considered as a ecofriendly reducing agent in natural indigo dyeing process.

\section{Acknowledgement}

The authors are indebted to Kasetsart University Research and Development Institute, Bangkhen Campus, Faculty of Science, The Graduate School and International Affairs Division, Kasetsart University, Thailand for financial support of this research. A great acknowledgement is also given to Department of Chemistry, Faculty of Science and Department of Textile Science, Faculty of Agro-Industry, Kasetsart University.

\section{References}

1. J. Balfour-Paul, Indigo, British Press, London (1998).

2. M. Moeyes, Natural dyeing in thailand, Cheney White Lotus, Bangkok. (1993).

3. N. Meksi, M.B. Ticha, M. Kechida and M.F. Mhenni. Journal of Cleaner Production, 24 (2012): 149-158.

4. S. Komboonchoo, A. Turcanu and T. Bechtold. Dyes and Pigments, 83(1) (2009): 21-30.

5. B. Mojca and V. Kokol. Dyes and Pigments, 46 (2008) : 299-309.

6. M.B. Ticha, N. Meksi, M. Kechida and M.F. Mhenni. International Journal of Environmental Research, 7(3) (2013) : 697-708.

7. V. Anne, Reduction and analysis methods of indigo. Doctoral dissertation, Turku University (2008).

8. M.B. Ticha, N. Meksi, M. Kechida and M.F.Mhenni. Chemical Industry and Chemical Engineering Quarterly, 20(4) (2014): 463-470.

9. R. M. Khan, Z. Uddin and D. Hossain. Middle-East Journal of Scientific Research, 22(7) (2014):10901095.

10. B.S. Richard and A. Harvey. Environmental Science and Technology, 38(14) (2004): 4034-4039.

11. S. Younsook, M. Choi and D.I. Yoo. Fashion and Textile, 1(1) (2014).

12. J. L. Jung, W.S. Shim, I. S. Kim and J. P. Kim. Fibers and Polymers, 6(3) (2005): 244-249.

13. J. N. Chakraborty: Indian Journal of Fibre and Textile Research, 39 (2004): 100-109. 